\title{
In situ X-Ray Diffraction Investigation of Surface Modifications in a Deep Rolling Process under Static Condition
}

\author{
Heiner Meyer ${ }^{1, a^{*}}$, Jérémy Epp ${ }^{1, b}$ and Hans-Werner Zoch ${ }^{1,2, c}$ \\ ${ }^{1}$ Stiftung Institut fuer Werkstofftechnik, Bremen, Germany \\ ${ }^{2}$ MAPEX Center for Materials and Processes, University of Bremen, Bremen, Germany \\ ahmeyer@iwt-bremen.de, bepp@iwt-bremen.de, 'zoch@iwt-bremen.de
}

\begin{abstract}
Keywords: 2D Strain Mapping, Process Signature, in situ X-Ray Diffraction, Deep Rolling, Internal Material Load, Material Modifications
\end{abstract}

\begin{abstract}
The deep rolling process is widely used as a finishing step, improving the surface properties through cold working and creation of residual strains. In the present investigations, in situ X-ray diffraction experiments were performed with a self-built deep rolling device at the European Synchrotron Radiation Facility (ESRF) in Grenoble, France. The measurements were performed with a cylindrical roller-tool on steel samples at beamline ID11 with a monochromatic beam of $50 \times 50$ $\mu \mathrm{m}$ in transmission. Several properties could be investigated based on the diffraction data. In particular, 2D-strain maps were determined in the range of several millimeters around the deep rolling tool. Based on the data collected during loading and after unloading, knowledge about the transient state leading to the resulting remaining property modifications like residual strains and plastic deformation were generated.
\end{abstract}

\section{Introduction}

The new Collaborative Research Centre "Process Signature" of the University of Aachen and Bremen concentrates on the study of process-independent surface modification mechanisms in order to achieve predictive manufacturing processes. After the process, a given volume near the surface shows property modifications including microstructural changes, increased hardness and generation of compressive residual strains. The internal strain field created during the process can be predicted by FEM simulations as well as contact mechanics theory depending on the applied load and contact geometry. However, an experimental verification of the real strain fields during the process does not exist up to now. The characterization of material modifications in mechanical processes is often constrained to ex situ analysis of the end state and a theoretical evaluation of the external factors that lead to the observed modifications. This approach often shows deviations in simulations and theoretical concepts applied to the process, because of unknown parameters. From external factors, however, a specific internal material load is found in the surface near region and in the region below, which directly influences the materials response to the applied mechanical load. Measurements of the internal material load and of the material modifications during the process show several problems depending on the utilized method. Optical methods with digital speckle photography allow measurements of surface strain fields but no direct analysis of the volume state as can be seen in the works of Johnson [1]. Another method is the integration of sensors inside the material, as done by Tausendfreund et al. [2]. The bondings between the resistive thin film and the material as well as the whole integration however introduce errors in the propagation of the strain field, shown by Dumstorff and Lang [3]. One further method for in situ process analysis is based on the use of high energy synchrotron radiation, which can penetrate steel samples up to a depth of several millimeters or even centimeters and give diffraction patterns from the illuminated crystalline structure along the beam path with sufficient intensity, like already used by Uhlmann et al. [4] for the analysis of an 
orthogonal cutting process. The method makes the measurement of a strain state during mechanical loading possible and gives additional information about texture, grain size, phase and specific elastic strain depending on the analysis as shown by Liss et al. [5]. In the present study monochromatic synchrotron radiation at the European Synchrotron Radiation Facility (ESRF) has been used to analyze the strain field and further material modifications of samples in transmission geometry during and after static loading with a deep rolling tool cylinder, to determine internal material load contribution and resulting residual strain state in situ respectively.

\section{Experimental methods}

Materials. The experiments were performed on quenched and tempered state of the $42 \mathrm{CrMo} 4$ (AISI 4140H) material. The chemical composition is given in Table 1.

Table 1 Chemical composition in wt.\% of steel AISI $4140 \mathrm{H}$ (EN 42CrMo4) in the samples

\begin{tabular}{|cccccccccc|}
\hline Steel & AISI & Heat treatment & $\begin{array}{c}\mathrm{C} \\
{[\%]}\end{array}$ & $\begin{array}{c}\mathrm{Cr} \\
{[\%]}\end{array}$ & $\begin{array}{c}\mathrm{Mo} \\
{[\%]}\end{array}$ & $\begin{array}{c}\mathrm{Mn} \\
{[\%]}\end{array}$ & $\begin{array}{c}\mathrm{Si} \\
{[\%]}\end{array}$ & $\begin{array}{c}\mathrm{S} \\
{[\%]}\end{array}$ & $\begin{array}{c}\text { Hardness } \\
{[\mathrm{HRC}]}\end{array}$ \\
\hline $\begin{array}{c}42 \mathrm{CrMo} 4 \\
(\mathrm{Q}+\mathrm{T})\end{array}$ & $4140 \mathrm{H}$ & $\begin{array}{c}850^{\circ} \mathrm{C} / 2 \mathrm{~h} \\
\text { Quenched to } 60^{\circ} \mathrm{C}(\mathrm{Oil}) / \\
\text { Tempered at } 400^{\circ} \mathrm{C} / 4 \mathrm{~h}\end{array}$ & 0.43 & 1.09 & 0.25 & 0.74 & 0.26 & $<0.001$ & $47 \pm 2$ \\
\hline
\end{tabular}

Experimental deep rolling device. For the experiments performed at the ESRF on beamline ID11EH1 a frame was constructed from aluminium profiles, which made the installation of an industrial deep rolling system with the full pressure range of up to 400 bar, provided through an external hydraulic fluid system, possible. Application of pressure was done in a top-down way and the sample positioning and movement was provided through a linear stage. Since the tool head is fixed in respect to the sample stage and the material state is homogenous isotropic, gauge volumes at different positions in respect to the contact point can be scanned during processing. The basic setup, a close up view of the sample with the deep rolling tool and the schematic layout are shown in Fig. 1.

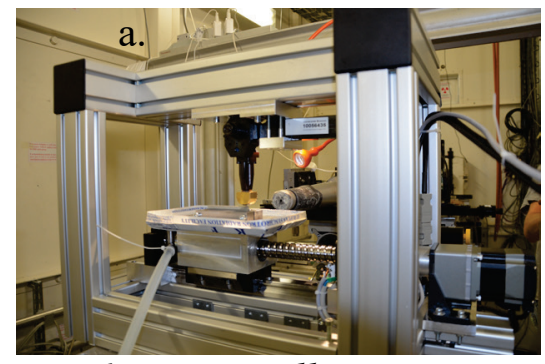

Fig. 1a. Deep rolling setup frame mounted in IDI1

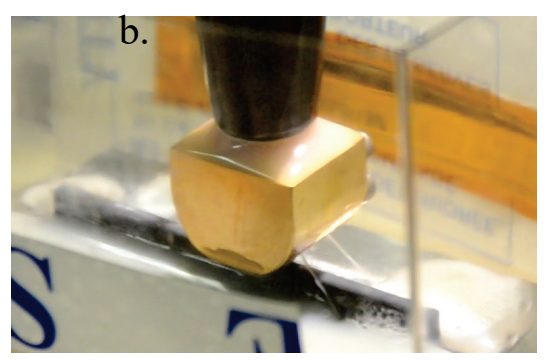

b. Deep rolling tool on sample during process

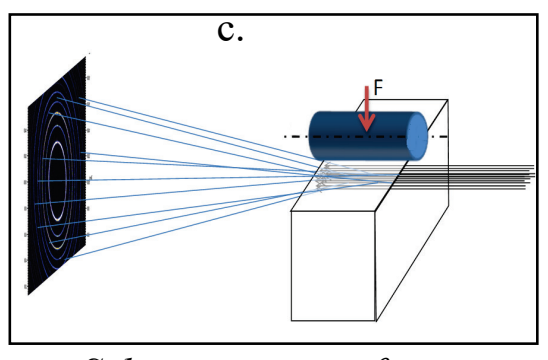

c. Schematic view of geometry

Experimental and measurement parameters. The experiment was carried out at beamline ID11 on experimental hutch 1 at the ESRF with high energy monochromatic radiation. The parameters for the measurement with the detector and the slit system settings are shown in Table 2.

Table 2 Experimental parameters for the measurements at IDI EH1

\begin{tabular}{|c|c|c|c|c|}
\hline $\begin{array}{c}\text { Photon } \\
\text { Energy }\end{array}$ & $\begin{array}{c}\text { Beam size } \\
{[\mu \mathrm{m}]}\end{array}$ & Detector & $\begin{array}{c}\text { Measurement } \\
\text { time }[\mathrm{s} / \text { meas. }\end{array}$ & 2Theta range \\
\hline $\begin{array}{c}100[\mathrm{keV}] \\
0.0123984[\mathrm{~nm}]\end{array}$ & $50 \times 50$ & $\begin{array}{c}\text { FReLoN 2D CCD } \\
(2048 \times 2048 \text { pixel })\end{array}$ & $\begin{array}{c}0.2 \mathrm{~s}(+1.0 \mathrm{~s} \text { for } \\
\text { axis movement })\end{array}$ & $\begin{array}{c}\text { Complete diffraction } \\
\text { rings } 0-10^{\circ}\end{array}$ \\
\hline
\end{tabular}

The detector was positioned at a distance of $273 \mathrm{~mm}$ from the sample behind the frame and the diffraction rings were measured in transmission geometry. A photon energy of $100 \mathrm{keV}$ was used to 
allow steel samples of sufficient width to be measured in transmission so that mechanical stability during the processing in the setup is ensured, while small beam dimensions are best suited for the spatial resolution of the strain field, which has a high gradients below the contact point in this geometry. Sample geometry was approximately cuboid with a $20 \mathrm{~mm}$ by $70 \mathrm{~mm}$ height and length, where the initial thickness of $3 \mathrm{~mm}$ from the wire-cut electrical discharge machining was further reduced by $100 \mu \mathrm{m}$ in the experimentally scanned area by electrolytic surface removal, giving a final sample thickness of $2.8 \mathrm{~mm}$ width .

The deep rolling tool for the static loading had a cylindric geometry with diameter of $13 \mathrm{~mm}$ and a length of $15 \mathrm{~mm}$, housed inside a brass tool head, and was machined from tungsten carbide (WC) material. It was applied at a pressure of 300 bar, corresponding to a force of $3100 \pm 100$ Newton along the width of the sample.

Methodical approach. With these parameters measurements of the 2D internal material load field around the deep rolling contact point were possible. Scans of the strains during static loading and the residual strain state after unloading were performed. As an example, the standard field in a static test consisted of a matrix of points with up to $50 \mu \mathrm{m}$ spatial resolution in the region near the contact point, with maximum grouping of points at the center along the y- and z-axis, which is shown in Fig. 2.

A full scanning field consists of 946 points in these measurements, where a range of $7.8 \mathrm{~mm}$ was scanned in horizontal direction and a zone of $4.15 \mathrm{~mm}$ depth from the surface of the sample was analyzed in vertical direction.

The movement of the setup frame on the diffractometer table for the different positions increases the total time for each point with $0.2 \mathrm{~s}$ measuring time $+1.0 \mathrm{~s}$ moving time to a mean value of $1.2 \mathrm{~s} /$ point, giving an effective measurement frequency of $0.78 \mathrm{~Hz}$.

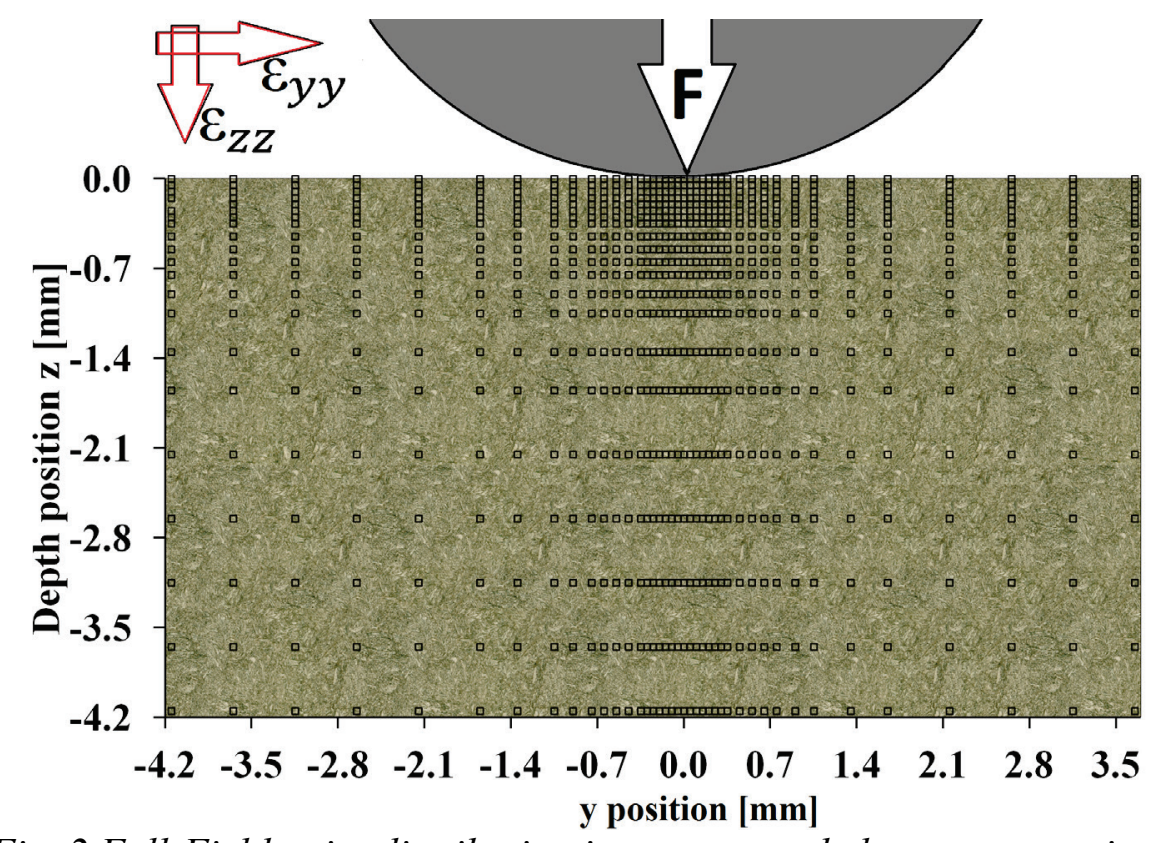

Fig. 2 Full-Field point distribution in scan range below contact point

Data analysis. Information from the gauge volume of $50 \mu \mathrm{m} \times 50 \mu \mathrm{m} \times 3 \mathrm{~mm}=0.0075 \mathrm{~mm}^{3}$ at each measurement point contains the information about the strain state, phase content and other parameters of the microstructural condition of the diffracting crystallites. Because of geometric and material parameters, uniform loading and deformation of the material by the rolling tool is achieved in the region of the beam path, which is along the x-direction.

$$
\varepsilon_{y y, z z}^{h k l}=\left(d_{y y, z z}^{h k l}-d_{0}^{h k l}\right) / d_{0}^{h k l} .
$$


Strain evaluation along orthogonal directions relies on caking, meaning azimuthal integration of a part of the diffraction ring that corresponds to the strain directions, as is shown in Fig.3. Using Eq. 1 the strain in the direction corresponding to the azimuthal section can be determined by using a $\mathrm{d}_{0^{-}}$ value of the unstrained material state, which was determined from a scan of the region before contact and compared with values from the edge points during and after loading. The strain evaluation is obtained from the $\alpha\{211\}$ reflex of the tempered martensite structure, as seen in the azimuthal integration in Fig. 4. This reflex is used because of its position around diffraction angle 6.05 deg with an intensity compared to the $\alpha\{110\}$ of $I_{\{211\}} / I_{\{110\}}=0.25$, achieving a mean error of $\Delta \varepsilon=35 \mu$ strains and $\triangle F W H M=0.0007 \mathrm{deg}$. Further analysis based on determination of lattice spacing from all available reflexes were not done yet but are planned in the next steps.

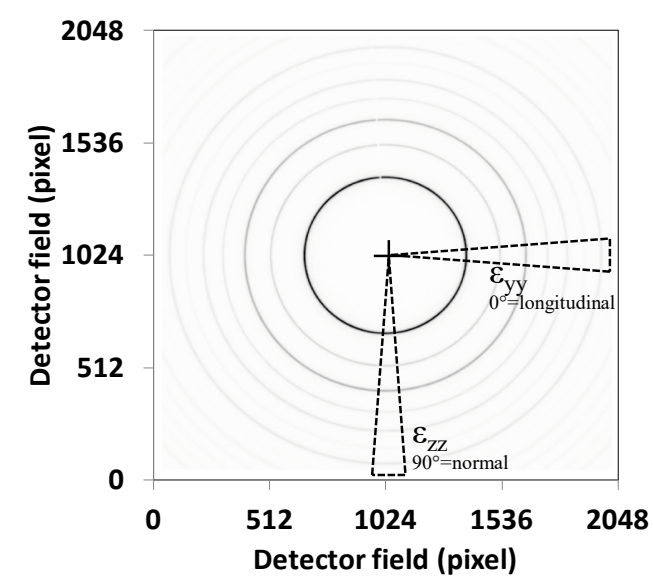

Fig. 3 Diffraction rings from detector readout

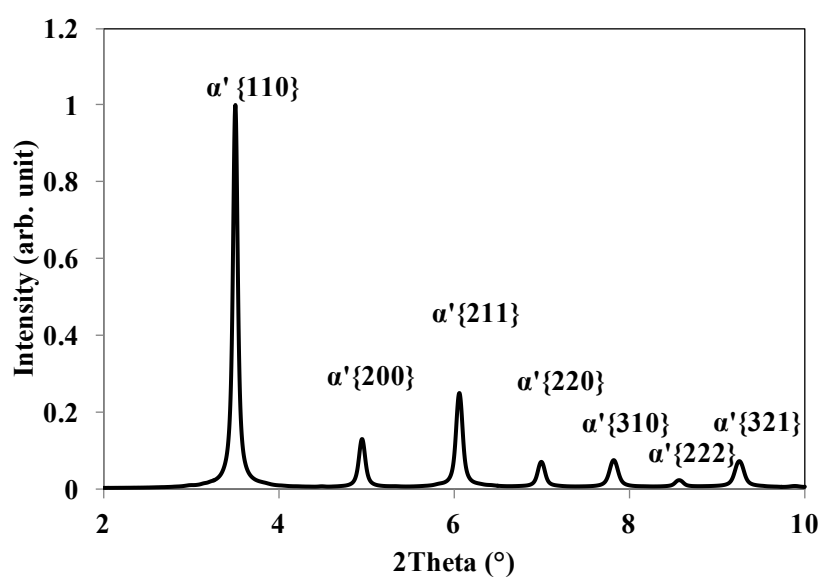

Fig. 4 Integrated diffraction pattern

with caking area in directions of $\varepsilon_{y y, z z}$

\section{Results}

2D strain maps. In order to observe the local variations of the strain state under the contact point, the obtained strain maps are only plotted for a region of $-1 \mathrm{~mm}<\mathrm{y}<+1 \mathrm{~mm}$ and $\mathrm{z}<-1 \mathrm{~mm}$. It can be seen in Fig. 7a and 7b that high load strains are measurable in a region around the contact point. Main strain field components lie in the direction of the applied force. The reconstruction of the strain maps is done point by point using Eq. 1 and yield during loading the following strain 2D fields on the $\mathrm{Q}+\mathrm{T}$ material. Loading strains of the $\varepsilon_{z z}$ component show a maximum of internal material load of $7500 \mu$ strains at contact point, decreasing in depth. The strain field expands laterally in the material at lower strain state, which can be observed along contour lines. In the $\varepsilon_{y y}$ direction compressive strains of up to $-2500 \mu$ strains are localized in the surface region to the side of the tool and tensile strains of up to $1500 \mu$ strains are found in depth of $-0.5 \mathrm{~mm}$ directly under the contact point. The fields show symmetric properties, were minor deviations from symmetry can be explained through experimental errors and slight variations in the local microstructure at the different measurement positions.

The resulting residual strains after unloading as seen in Fig. 8 are concentrated in the same region, while compressive residual strains up to $-580 \mu$ strains were measured in the $\varepsilon_{y y}$ direction to both sides of the contact point and tensile strains of up to $600 \mu$ strains under the contact point in the $\varepsilon_{z z}$ component. Material modifications are not only found in depth direction under the roller but also sideways displaced material by plastic flow exhibits a compressive residual strain state.

Determination of the residual stress state in this case is impeded by the possibility of a triaxial stress state with non-zero components along the sample thickness. A modified plain stress state approach will be tested, while further ex situ measurements of the processed samples and simulations are currently ongoing and will give better understanding of the stress state. 

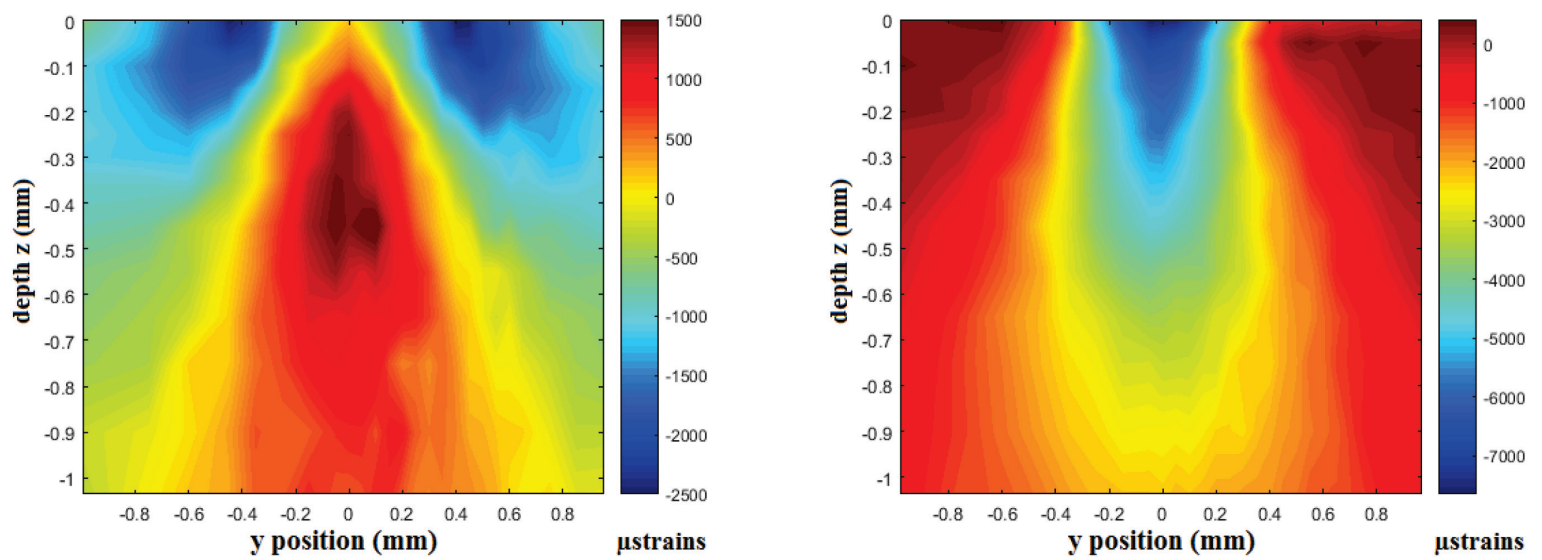

Fig. 7a 2D strain map of $\varepsilon_{y y}$ during loading (300 bar) Fig. $7 b 2 D$ strain map of $\varepsilon_{z z}$ during loading

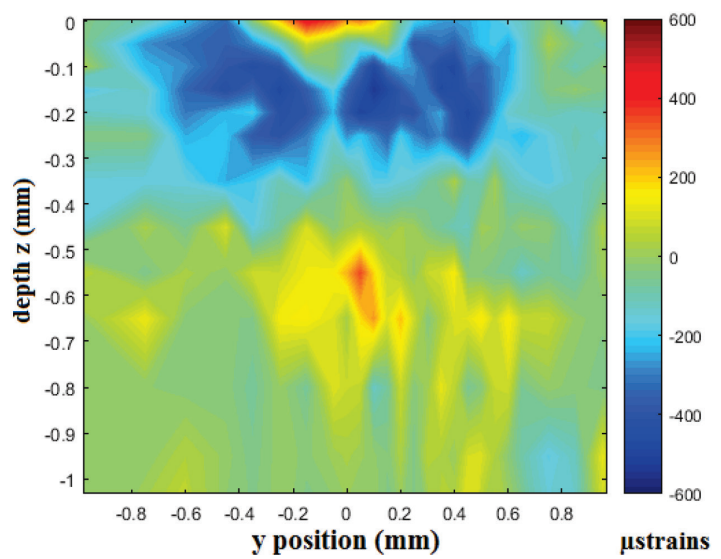

Fig. 8a $2 D$ strain map of $\varepsilon_{y y}$ after unloading

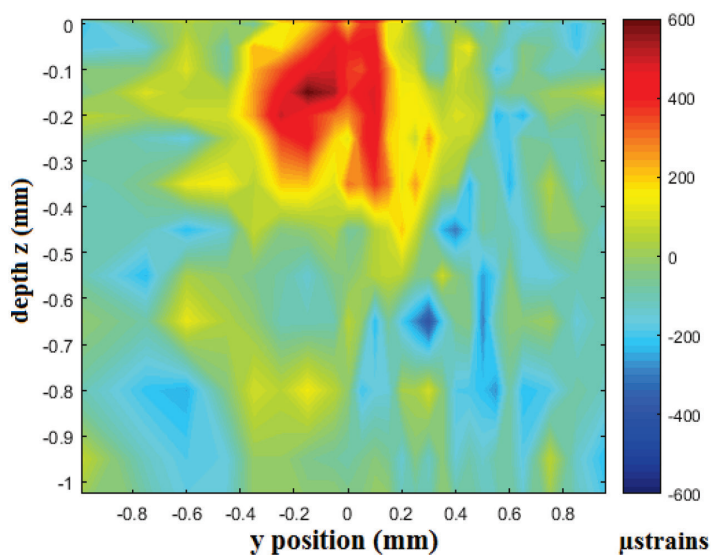

Fig. $8 b 2 D$ strain map of $\varepsilon_{z z}$ after unloading

FWHM analysis. The integrated $\{211\}$ peaks in $90^{\circ}\left(\varepsilon_{z z}\right)$ direction were fitted with a pseudovoigt function (PV) at every point of the 2D map and the variation of Full-Width at Half-Maximum (FWHM) of the peaks is displayed in the same way as the strains.

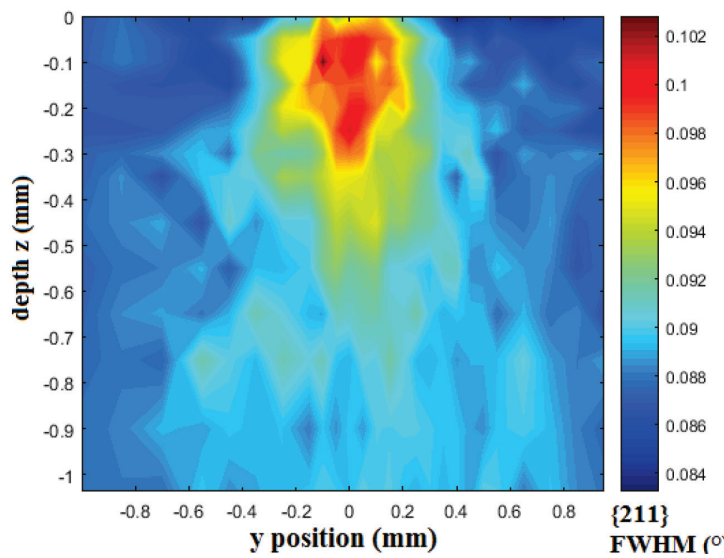

Fig. 9a FWHM 2D map during loading

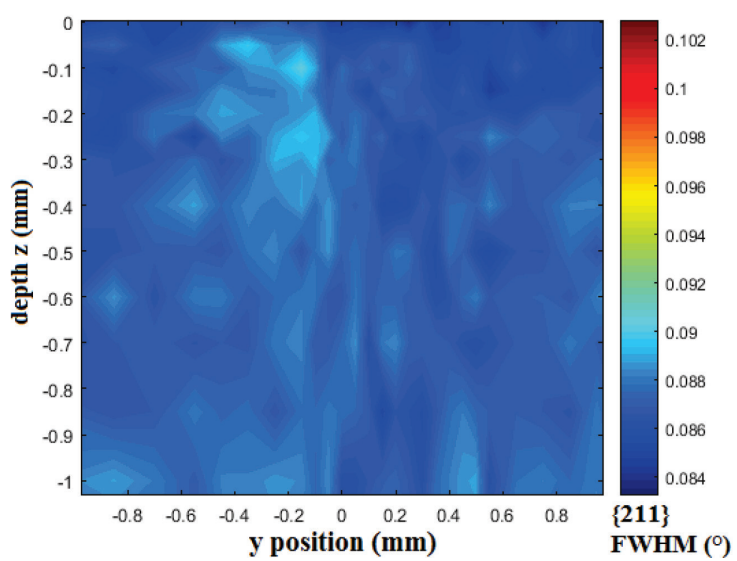

Fig. $9 b$ FWHM in the same region after unloading

As can be seen in Fig. 9 a strong difference in FWHM values during loading and after unloading is present. If the FWHM increase would only have been resulting from plastic deformation, no change should have take place after unloading. Therefore, the strong increase of FWHM below the contact point during loading can be attributed to inhomogeneous elastic strains, either of $1^{\text {st }}$ kind (strain inhomogeneity in the illuminated zone, e. g. over thickness or within the $50 \mu \mathrm{m}$ beam size) or/and of $2^{\text {nd }}$ kind (intergranular strains between crystallites during load, as seen by Morooka et al. 
[6]).Further evaluations are needed and currently ongoing for deeper analysis and interpretation of these results. On the other hand, no significant increase of FWHM is observed after unloading. In this case, a similar behavior as reported by Zinn et al. is expected, where no pronounced peak width variation could be observed for quenched and tempered steel with an initial hardness close to $500 \mathrm{HV}$ (49 HRC) [7]. Due to the mechanical energy input, already present dislocations can decrease due to annihilation effects, while new dislocations are created, which results in an almost constant FWHM for this material state.

\section{Conclusion}

It was shown that using monochromatic high energy synchrotron radiation, spatially-resolved measurements of internal material load during the deep rolling process can be performed with high spatial resolution. First results showing the 2D strain fields from spatially-resolved gauge volumes distributed around the point of contact inside the material were presented. The symmetric field with characteristics predicted by theory and simulation was found during the contact of the cylindrical deep rolling tool under static condition. The available data gives the prospect of detailed comparison of the internal material load state with the resulting residual strains as well as further material modifications. In further analyses of the data, deeper investigation of the FWHM distribution and resulting dislocation density will be performed. As well, stress calculations will be done by using different assumptions, based on FEM simulation and ex-situ investigations of the residual stress state of the processed samples. These are currently ongoing for deeper evaluation and interpretation of the experiments and will be extended to varying tool pressure and to dynamic processes with tool movement.

\section{Acknowledgements}

The authors gratefully acknowledge the German Research Foundation (DFG) for their financial support of the project $\mathrm{C} 01$ in the Transregional Collaborative Research Center SFB/TRR 136 "Process Signatures". The in situ experiments were performed on beamline ID11 at the ESRF, Grenoble, France. We are grateful to J.P. Wright at the ESRF for providing assistance in using beamline ID11.

\section{References}

[1] P. Johnson, Strain field measurements with dual-beam digital speckle photography, Optics and lasers in engineering 30(3) (1998) 315-326. http://dx.doi.org/10.1016/S0143-8166(98)00021-9

[2] A. Tausendfreund, D. Stöbener, G. Dumstorff, M. Sarma, C. Heinzel, W. Lang and G. Goch, Systems for locally resolved measurements of physical loads in manufacturing processes, CIRP Annals - Manufacturing Technology 64(1) (2015) 495-498.

[3] G. Dumstorff, W. Lang, Investigations on the Impact of Material-Integrated Sensors with the Help of FEM-Based Modeling, Sensors $15 \quad$ (2015) 2336-2353. http://dx.doi.org/10.3390/s150202336

[4] E. Uhlmann, R. Gerstenberger, S. Herter, T. Hoghé, W. Reimers, B. Camin, T. Fischer, In situ strain measurement in the chip formation zone during orthogonal cutting, Prod. Engineer. 5(1) (2011) 1-8. http://dx.doi.org/10.1007/s11740-010-0266-x

[5] K.D. Liss, A. Bartels, A., Schreyer, H. Clemens, High-energy X-rays: a tool for advanced bulk investigations in materials science and physics, Textures Microstruct. 35(3-4) (2003) 219-252. http://dx.doi.org/10.1080/07303300310001634952

[6] S. Morooka, Y. Tomota, T. Kamiyama, Heterogeneous deformation behavior studied by in situ neutron diffraction during tensile deformation for ferrite, martensite and pearlite steels, ISIJ international 48(4) (2008) 525-530. http://dx.doi.org/10.2355/isijinternational.48.525

[7] M. Lebsanft, M. Tiffe, A. Zabel, W. Zinn, D. Biermann, B. Scholtes, Residual Stresses in Different Heat Treated Workpieces after Turning, Advanced Materials Research 996 (2014) 652-657. http://dx.doi.org/10.4028/www.scientific.net/AMR.996.652 